\title{
Safety of Amiodarone in Ventricular Arrhythmia in Patients Admitted in Bangabandhu Sheikh Mujib Medical University
}

\author{
SUJOY KUMAR SAHA ${ }^{1}$, MANZOOR MAHMOOD ${ }^{1}$, DIPAL KRISHNA ADHIKARY ${ }^{1}$, SYED ALI AHSAN ${ }^{1}$, \\ CHAUDHURY MESHKAT AHMED ${ }^{1}$, MD. HARISUL HOQUE ${ }^{1}$, M.A MUQUEET ${ }^{1}$, M M MUSTAFA ZAMAN $^{1}$, \\ MD. ABU SALIM ${ }^{1}$, MD. FAKHRUL ISLAM KHALED ${ }^{1}$, MD. ARIFUL ISLAM JOARDER ${ }^{1}$, MRM MANDAL ${ }^{1}$, \\ MOHAMMAD WALIDUR RAHMAN ${ }^{2}$, MD.AZHARUL ISLAM ${ }^{1}$, \\ A.K.M. IMTIAZ AKAND ${ }^{1}$, FYSAL FARUQ ${ }^{1}$, SAJAL KRISHNA BANERJEE ${ }^{1}$ \\ ${ }^{1}$ Department of Cardiology, Bangabandhu Sheikh Mujib Medical University (BSMMU), Dhaka, ${ }^{2}$ National Institute of \\ Cardiovascualr Disease (NICVD), Dhaka
}

Address of Correspondents: Dr. Sujoy Kumar Saha, Resident (Phase-B), Department of Cardiology, Bangabandhu Sheikh Mujib Medical University, Dhaka, Email: sujoybsmmu@gmail.com.

\begin{abstract}
Background: Amiodarone is the most effective antiarrhythmic medications available today for the treatment of both atrial and ventricular arrhythmias. It is an iodinated benzofuran derivative with demonstrated efficacy against a range of cardiac arrhythmias, including atrial fibrillation, paroxysmal supraventricular tachycardias, and life-threatening ventricular arrhythmias.

Objective: To evaluation the status of amiodarone with therapeutic dose in Bangladeshi population.

Materials and Methods: The quasi experimental study was conducted in the Department of Cardiology in Bangabandhu Sheikh Mujib Medical University (BSMMU), Shahbagh, Dhaka during April, 2019 to March, 2020 Patients got admitted in the Department of Cardiology, BSMMU, consecutive patients who had been treated with amiodarone for arrhythmia were included in this study. Patients without an amiodarone prescription were assumed and patients who will not give informed written consent were excluded in this study.

Results: The most common adverse event was bradycardia or conduction disturbance (9.0\%) followed by 4(2.2\%) thyroid toxicity, 3(1.7\%) hepatic toxicity, 2(1.1\%) eye toxicity and $1(0.6 \%)$ pulmonary toxicity. In multi variable logistic regression, bradycardia or conduction disturbance, amiodarone daily dose ( $\geq 300 \mathrm{mg})$ and duration of amiodarone (>4 month) was found to be significantly $(p<0.05)$ associated with adverse effects of amiodarone.

Conclusion: The most common adverse event was bradycardia or conduction disturbance followed by thyroid toxicity, hepatic toxicity, eye toxicity and pulmonary toxicity. Bradycardia or conduction disturbance, amiodarone daily dose ( $\geq 300 \mathrm{mg}$ ) and duration of amiodarone (>4 month) was found to be significantly associated with adverse effects of amiodarone.
\end{abstract}

University Heart Journal 2021; 17(2): 118- 121

Introduction:

Amiodarone is the most effective antiarrhythmic medications available today for the treatment of both atrial and ventricular arrhythmias. Its efficacy is likely related to diverse effects on a number of cardiac receptors. ${ }^{1}$

Amiodarone is commonly utilized for treating both supraventricular and ventricular arrhythmias. While this drug is a very effective antiarrhythmic agent, it also leads to many well-known side effects involving a variety of organs such as the thyroid, liver, lungs, and eyes including many that are dose- and duration-dependent. ${ }^{2}$ The use of amiodarone must be balanced between the drug's potentially serious adverse effects and its antiarrhythmic effects. However, current guidelines still recommend that amiodarone be chosen as the first-line therapy in some patient groups. ${ }^{3}$

Amiodarone, a potent antiarrhythmic drug that is useful for both atrial and ventricular arrhythmia, has a combination of $\beta$-blockade, calcium channel blockade, and class III antiarrhythmic effects. In patients with acute-onset AF and also with impaired left ventricular function, amiodarone or digoxin has been recommended because of a minimal negative inotropic effect. ${ }^{4}$ In patients with persistent AF, amiodarone has been shown to be effective in achieving and maintaining sinus rhythm (50\%-70\%) in some studies. ${ }^{5-7}$ However, amiodarone has serious systemic adverse effects; furthermore, amiodarone has been suggested to be associated with an increase in mortality in patients with severe acute or chronic heart failure.

Amiodarone is an iodinated benzofuran derivative with demonstrated efficacy against a range of cardiac arrhythmias, including atrial fibrillation, paroxysmal supraventricular tachycardias, and life-threatening ventricular arrhythmias. Despite its many side effects, some of which may be serious, orally administered amiodarone 
has been widely used as a highly effective alternative to more conventional antiarrhythmic therapies in patients with refractory, ventricular arrhythmias.

\section{Materials and Methods:}

The quasi experimental study was conducted in the Department of Cardiology in Bangabandhu Sheikh Mujib Medical University, Shahbagh, Dhaka during April, 2019 to March, 2020 Patients got admitted in the Department of Cardiology, BSMMU, consecutive patients who had been treated with amiodarone for arrhythmia were included in this study. Patients without an amiodarone prescription were assumed and patients who will not give informed written consent were excluded in this study. All patients get guideline directed therapy including revascularization. Loading dose followed by maintenance dose of amiodarone was given and recorded. Baseline demographic, ECG (significant number of PVC, multifocal in origin, $\mathrm{R}$ on $\mathrm{T}$ phenomenon, couplets, triplets, short run), Echo, 24H Holter ECG (significant number of PVC, multifocal in origin, $\mathrm{R}$ on $\mathrm{T}$ phenomenon, couplets, triplets, short run, non sustained VT) or cardiac monitoring record, electrolyte, creatinine, thyroid profile, eye condition was kept. Patients were followed up at end of first, third \& sixth month. Occurrence of symptoms of arrythmia, hospitalization form arrhythmia and cardiac death were noted. Focused clinical examination of eye, skin, nervous system, thyroid status, cardiovascular, respiratory system was done and 12 lead ECG was taken in each visit. If any adverse effects of amiodarone arises, then the patient was treated according to standard guideline and amiodarone was discontinued in relevant case. $24 \mathrm{H}$ Holter ECG to look for correction of index arrhythmia or appearance of newer arrhythmia, thyroid function test, X-ray of chest, liver function test was done after 6 months in asymptomatic cases, and early in clinically relevant cases. Data was recorded in preformed data sheet. Treatment outcome and complications was analyzed. Statistical analyses were carried out by using the Statistical Package for Social Sciences (SPSS) version 23.0 for Windows Software. Continuous data were expressed as mean \pm standard deviation (SD) and categorical data were expressed as frequency and percentages. Mean and standard deviation were computed for quantitative variables and was analyzed by paired ttest. Chi square test was used for categorical variables. P values $<0.05$ was considered as statistically significant.

\section{Result:}

Smoker, amiodarone daily dose and duration of amiodarone treatment higher in side effects group than without side effects group. The difference were not statistically significant $(p>0.05)$ between two group (Table-1). The most common adverse event was bradycardia or conduction

Table-I

Baseline clinical characteristics of the study patients $(n=178)$

\begin{tabular}{|c|c|c|c|c|c|}
\hline & \multicolumn{2}{|c|}{ Side effects $(n=26)$} & \multicolumn{2}{|c|}{ Without side effects $(n=152)$} & \multirow[t]{2}{*}{$p$ value } \\
\hline & $\mathrm{n}$ & $\%$ & $\mathrm{n}$ & $\%$ & \\
\hline \multicolumn{6}{|l|}{ Demographic variable } \\
\hline Male & 15 & 57.7 & 89 & 58.6 & 0.934 \\
\hline Mean age (years) & 65.7 & \pm 10.8 & 64.5 & \pm 11.9 & 0.631 \\
\hline Mean BMI $\left(\mathrm{kg} / \mathrm{m}^{2}\right)$ & 22.9 & \pm 4.0 & 22.3 & \pm 3.7 & 0.451 \\
\hline \multicolumn{6}{|l|}{ Co-morbidities } \\
\hline Diabetes & 6 & 23.1 & 28 & 18.4 & 0.372 \\
\hline Hypertension & 7 & 26.9 & 25 & 16.4 & 0.155 \\
\hline Dyslipidemia & 7 & 26.9 & 32 & 21.1 & 0.503 \\
\hline Coronary artery disease & 13 & 50.0 & 54 & 35.5 & 0.159 \\
\hline Congestive heart failure & 4 & 15.4 & 18 & 11.8 & 0.405 \\
\hline Stroke & 3 & 11.5 & 12 & 7.9 & 0.379 \\
\hline Smoker & 9 & 34.6 & 28 & 18.4 & 0.060 \\
\hline \multicolumn{6}{|l|}{ Cardiac status } \\
\hline Ischemic heart disease & 1 & 3.8 & 2 & 1.3 & 0.379 \\
\hline Acute decompensate chronic heart failure & 2 & 7.7 & 3 & 2.0 & 0.155 \\
\hline Cardiac arrest & 3 & 11.5 & 9 & 5.9 & 0.247 \\
\hline \multicolumn{6}{|l|}{ Cause of amiodarone use } \\
\hline Atrial fibrillation & 19 & 73.1 & 113 & 74.3 & \\
\hline Ventricular premature beat & 2 & 7.7 & 10 & 6.6 & 0.977 \\
\hline Ventricular tachycardia & 5 & 19.2 & 29 & 19.1 & \\
\hline Mean amiodarone daily dose (mg) & 299.4 & \pm 86.7 & 264.8 & \pm 91.3 & 0.074 \\
\hline Mean duration of amiodarone (month) & 4.9 & \pm 1.8 & 4.1 & \pm 2.2 & 0.081 \\
\hline
\end{tabular}


disturbance $(9.0 \%)$ followed by $4(2.2 \%)$ thyroid toxicity, $3(1.7 \%)$ hepatic toxicity, $2(1.1 \%)$ eye toxicity and $1(0.6 \%)$ pulmonary toxicity (Table-2). In multi variable logistic regression, bradycardia or conduction disturbance, amiodarone daily dose ( $\geq 300 \mathrm{mg}$ ) and duration of amiodarone ( $>4$ month) was found to be significantly $(p<0.05)$ associated with adverse effects of amiodarone (Table-3).

Table-II

Reasons for discontinuation of therapy

\begin{tabular}{lcc}
\hline Adverse effect & Frequency & Percentage \\
\hline Bradycardia or conduction & 16 & 9.0 \\
disturbance & & \\
Thyroid toxicity & 4 & 2.2 \\
Hepatic toxicity & 3 & 1.7 \\
Eye toxicity & 2 & 1.1 \\
Pulmonary toxicity & 1 & 0.6 \\
\hline
\end{tabular}

Table-III

Multivariate analysis predictors for adverse effects of amiodarone

\begin{tabular}{lcc}
\hline Variable & OR $(95 \% \mathrm{CI})$ & $p$ value \\
\hline Age $(\geq 65$ years $)$ & $0.79(0.04-14.83)$ & 0.875 \\
BMI $\left(\geq 25 \mathrm{~kg} / \mathrm{m}^{2}\right)$ & $0.82(0.19-3.99)$ & 0.809 \\
Coronary artery disease & $1.08(0.43-2.73)$ & 0.864 \\
$\begin{array}{l}\text { Bradycardia or conduction } \\
\text { disturbance }\end{array}$ & $3.05(1.06-8.82)$ & 0.039 \\
$\begin{array}{l}\text { Pulmonary disease } \\
\text { Thyroid dysfunction }\end{array}$ & $0.95(0.52-1.14)$ & 0.169 \\
Liver disease & $1.23(0.41-12.83)$ & 0.876 \\
$\begin{array}{l}\text { Amiodarone daily dose } \\
(\geq 300 \text { mg })\end{array}$ & $3.26(0.51-20.86)$ & 0.212 \\
$\begin{array}{l}\text { Duration of amiodarone } \\
(>4 \text { month })\end{array}$ & $3.63(1.18-8.47)$ & 0.022 \\
\hline
\end{tabular}

\section{Discussion:}

In current study observed that smoker, amiodarone daily dose and duration of amiodarone treatment higher in side effects group than without side effects group. The difference were not statistically significant $(\mathrm{p}>0.05)$ between two group. Kim et al. ${ }^{8}$ study observed there were no signifi-cant differences between the two groups, except for the mean dose and total duration of amiodarone treatment. The mean daily dose of amiodarone was higher in pa-tients with adverse events than in those without adverse events ( $231 \pm 130 \mathrm{mg}$ vs. $208 \pm 102 \mathrm{mg}, p=0.039)$. The du-ration of amiodarone treatment was longer in patients with side effects than in those without $(813 \pm$
$1,086$ days vs. $425 \pm 730$ days, $p<0.001)$. In a randomized controlled trial by Roy et al. ${ }^{6}, 18 \%$ of patients who had received $200 \mathrm{mg}$ /day amiodarone for the maintenance of sinus rhythm discontinued taking the drug because of adverse events during a 16-month follow-up. In another trial with a similar study design, the incidence of adverse effects requiring discontinua-tion was $12.3 \%$ during the first year. ${ }^{9}$

The guidelines published by the North American Society of Pacing and Electrophysiology in 2000 estimated that the incidence of adverse effects of amiodarone was 15\% during the first year and as high as 50\% with long-term therapy. ${ }^{10}$

Julian et al. ${ }^{11}$ demonstrated that $38.5 \%$ of patients in the amiodarone group (200 mg/day) discontinued med-ication, compared with $21.4 \%$ of those in the placebo group, during the 21-month study period. Bardy et al. ${ }^{12}$ demonstrated study drug discontinuation rates of $32 \%$ in the amiodarone group and $22 \%$ in the placebo group among patients with congestive heart failure. Their study used a median dose of $300-\mathrm{mg} /$ day amiodarone and a median study follow-up period of 45.5 months. ${ }^{12}$

In present study showed that the most common adverse event was bradycardia or conduction disturbance $(9.0 \%)$ followed by $4(2.2 \%)$ thyroid toxicity, $3(1.7 \%)$ hepatic toxicity, $2(1.1 \%)$ eye toxicity and $1(0.6 \%)$ pulmonary toxicity. Kim et al. ${ }^{8}$ reported the most frequent adverse effect was brady-cardia or conduction disturbance, which occurred in 88 patients $(9.5 \%)$. Thyroid and hepatic toxicities occurred in 23 patients $(2.5 \%)$ and 20 patients $(2.2 \%)$, respectively. The chronic use of low dose amiodarone was associated with an increased risk of bradycardia compared with placebo $(3.3 \%$ vs. $1.4 \%)$ in a previous meta-analysis. ${ }^{13}$ An additional study reported that the overall incidence of bradycardia was $5 \% .{ }^{10}$ This high iodine content and the direct toxic effects of amiodarone on the thyroid parenchyma alter thyroid function, ${ }^{14}$ and the incidence of amiodarone-induced thyroid dysfunction in previous studies was $14 \%$ to $18 \% .{ }^{15}$ Hepatotoxicity due to amiodarone was $1.7 \%$ in the current study, which is considerably lower than the previously reported incidences of $14 \%$ to $82 \%,{ }^{16}$ among which $20 \%$ to $40 \%$ of patients required drug discontinuation because of hepatotoxicity. ${ }^{17}$ Pulmonary toxicity due to amiodarone was found $0.6 \%$ in this study. Recent studies reported that the incidence of amiodarone-induced pulmonary toxicity (AIPT) was $5 \%$ to $13 \%{ }^{18}$

In this study observed that in multi variable logistic regression, bradycardia or conduction disturbance, amiodarone daily dose $(\geq 300 \mathrm{mg})$ and duration of amiodarone ( $>4$ month) was found to be significantly $(p<0.05)$ associated with adverse effects of amiodarone. Kim et al. ${ }^{8}$ 
observed the independent risk factors for amiodarone related adverse effects, multiple logistic regression analyses were performed. After controlling for confounders, the duration of amiodarone treatment was the only independent risk factor for adverse events (odds ratio, 1.21; 95\% confi-dence interval, 1.03 to $1.41 ; p=0.016$, per year). Previous studies showing that the cumulative admin-istered dose of amiodarone was a major risk factor for amiodarone-induced organ toxicity. ${ }^{10,19,20}$ Age, gender, and underlying disease have also been suggested to be predictors of specific organ toxicities; ${ }^{21-23}$ however, these factors were not associated with the overall adverse effects of amiodarone in the current study. We also performed multivariate analyses to identify independent predictors for specific organ toxicities, but the data were limited because of the small number of adverse events. Doyle and $\mathrm{Ho}^{24}$ study showed cessation of amiodarone therapy because of intolerable adverse effects was more common compared with a placebo or rate control drug (10.7 vs 1.9 per 100 patient-years; RR, 3.0; 95\% CI, 1.4$6.2 ; \mathrm{P}<0.001)$, but amiodarone was not associated with an increased incidence of hospitalizations (RR, 1.1; 95\% CI, $0.6-2.1 ; \mathrm{P}=0.77)$.

\section{Conclusion:}

The most common adverse event was bradycardia or conduction disturbance followed by thyroid toxicity, hepatic toxicity, eye toxicity and pulmonary toxicity. , Bradycardia or conduction disturbance, amiodarone daily dose ( $\geq 300 \mathrm{mg})$ and duration of amiodarone ( $>4$ month) was found to be significantly associated with adverse effects of amiodarone.

\section{References:}

1. Vyskocilova EH, Grundmann M, Duricova J, Kacirova I. Therapeutic monitoring of amiodarone: pharmacokinetics and evaluation of the relationship between effect and dose/ concentration. Biomedical Papers of the Medical Faculty of Palacky University in Olomouc. 2017;161(2);134-43.

2. Chokesuwattanaskul R, Shah N, Chokesuwattanaskul S, Liu Z, Thakur R. Low-dose amiodarone is safe: a systematic review and meta-analysis. The Journal of Innovations in Cardiac Rhythm Management. 2020;11(4):4054.

3. Epstein AE, Olshansky B, Naccarelli GV, Kennedy JI, Murphy EJ, Goldschlager N. Practical management guide for clinicians who treat patients with amiodarone. Am J Med. 2016;129(5):468-75.

4. Iqbal MB, Taneja AK, Lip GY, Flather M. Recent developments in atrial fibrillation. BMJ. 2005;330(7485):238-43.

5. Kochiadakis GE, Igoumenidis NE, Marketou ME, Solomou MC, Kanoupakis EM, Vardas PE. Low-dose amiodarone versus sotalol for suppression of recurrent symptomatic atrial fibrillation. Am J Cardiol. 1998;81(8):995-98.

6. Roy D, Talajic M, Dorian P, Connolly S, Eisenberg MJ, Green $\mathrm{M}$, et al. Amiodarone to prevent recurrence of atrial fibrillation. N Engl J Med. 2000;342(13):913-20.
7. Chun SH, Sager PT, Stevenson WG, Nademanee K, Middlekauff HR, Singh BN. Long-term efficacy of amiodarone for the maintenance of normal sinus rhythm in patients with refractory atrial fibrillation or flutter. Am J Cardiol. 1995;76(1):47-50.

8. Kim HL, Seo JB, Chung WY, Kim SH, Kim MA, Zo JH. The incidence and predictors of overall adverse effects caused by low dose amiodarone in real-world clinical practice. Korean $\mathrm{J}$ Intern Med 2014;29:588-96.

9. AFFIRM First Antiarrhythmic Drug Substudy Investi-gators. Maintenance of sinus rhythm in patients with atrial fibrillation: an AFFIRM substudy of the first antiar-rhythmic drug. J Am Coll Cardiol 2003;42:20-29.

10. Goldschlager N, Epstein AE, Naccarelli G, Olshansky B, Singh B. Practical guidelines for clinicians who treat patients with amiodarone: Practice Guidelines Subcom-mittee, North American Society of Pacing and Electro-physiology. Arch Intern Med 2000;160:1741-48.

11. Julian DG, Camm AJ, Frangin G, et al. Randomised trial of effect of amiodarone on mortality in patients with leftventricular dysfunction after recent myo-cardial infarction: EMIAT. European Myocardial Infarct Amiodarone Trial Investigators. Lancet 1997;349:667-74.

12. Bardy GH, Lee KL, Mark DB, et al. Amiodarone or an im-plantable cardioverter-defibrillator for congestive heart failure. N Engl J Med 2005;352:225-37.

13. Vorperian VR, Havighurst TC, Miller S, January CT. Ad-verse effects of low dose amiodarone: a meta-analysis. J Am Coll Cardiol 1997;30:791-98.

14. Basaria S, Cooper DS. Amiodarone and the thyroid. Am J Med 2005;118:706-14.

15. Martino E, Bartalena L, Bogazzi F, Braverman LE. The effects of amiodarone on the thyroid. Endocr Rev 2001; 22:240-54.

16. Babatin M, Lee SS, Pollak PT. Amiodarone hepatotoxicity. Curr Vasc Pharmacol 2008;6:228-36.

17. Podrid PJ. Amiodarone: reevaluation of an old drug. Ann Intern Med 1995;122:689-700.

18. Ernawati DK, Stafford L, Hughes JD. Amiodarone-induced pulmonary toxicity. Br J Clin Pharmacol 2008;66:82-87.

19. HafCI, Love JC, Alpert JS, Asdourian GK, Sloan KC. Efficacy and safety of long-term amiodarone in treatment of cardiac arrhythmias: dosage experience. Am Heart J 1983;106(4 Pt 2):935-43.

20. Santangeli P, Di Biase L, Burkhardt JD, et al. Exam-ining the safety of amiodarone. Expert Opin Drug Saf 2012;11: $191-14$.

21. Jackevicius CA, Tom A, Essebag V, et al. Population-level incidence and risk factors for pulmonary toxicity asso-ciated with amiodarone. Am J Cardiol 2011;108:705-10.

22. Camus P, Martin WJ 2nd, Rosenow EC 3rd. Amiodarone pulmonary toxicity. Clin Chest Med 2004;25:65-75.

23. Yamada Y, Shiga T, Matsuda N, Hagiwara N, Kasanuki H. Incidence and predictors of pulmonary toxicity in Japanese patients receiving low-dose amiodarone. Circ J 2007;71: 1610-16.

24. Doyle JF, Ho KM. Benefits and Risks of Long-term Amiodarone Therapy for Persistent Atrial Fibrillation: A Metaanalysis. Mayo Clin Proc. 2009;84(3):234-42. 